\title{
Type II-Metacaspases are involved in cell stress but not in cell death in the unicellular green alga Dunaliella tertiolecta
}

\author{
M. Teresa Mata ${ }^{1,8}$, Armando Palma $^{1}$, Candela García-Gómez ${ }^{1, \#}$, María López-Parages ${ }^{1}$, Víctor Vázquez ${ }^{1}$, \\ Iván Cheng-Sánchez ${ }^{2}$, Francisco Sarabia ${ }^{2}$, Félix López-Figueroa ${ }^{1}$, Carlos Jiménez ${ }^{1}$ and María Segovia ${ }^{1, *}$ \\ ${ }^{1}$ Department of Ecology, Faculty of Sciences, University of Málaga, Blvd. Louis Pasteur s/n, 29071-Málaga, Spain. \\ ${ }^{2}$ Department of Organic Chemistry, Faculty of Sciences, University of Málaga, Blvd. Louis Pasteur s/n, 29071-Málaga, Spain. \\ \& Present address: Antofagasta Bioinnovation Center (CBIA), Department of Biotechnology, Faculty of Marine Sciences and Biological \\ Resources. University of Antofagasta, Antofagasta, Chile. \\ \# Present address: Spanish Oceanographic Institute, Puerto Pesquero, 29640-Fuengirola, Málaga, Spain. \\ * Corresponding Author: \\ María Segovia, Department of Ecology, Faculty of Sciences, University of Málaga, Blvd. Louis Pasteur s/n, 29071-Málaga, Spain; \\ E-mail: segovia@uma.es
}

\begin{abstract}
Ultraviolet radiation (UVR; $280-400 \mathrm{~nm}$ ) has a great impact on aquatic ecosystems by affecting ecophysiological and biogeochemical processes as a consequence of the global change scenario generated by anthropogenic activities. We studied the effect of PAR (P)+UVA (A)+UVB (B) i.e. PAB, on the molecular physiology of the unicellular green alga Dunaliella tertiolecta for six days. We assessed the relationship between the triggered UVR stress response and metacaspases and caspase-like (CL)activities, which are proteases denoted to participate in cell death (CD) in phytoplankton. UVR inhibited cell growth and in vivo chlorophyll a fluorescence but did not cause cell death. Western blot analyses reflected that Type-II metacaspases (MCs) are present and appear to be involved in UVR induced-cell stress but not in dark-induced CD in D. tertiolecta. Enzyme kinetics revealed that cleavage of the MCs-reporter substrates RVRR, QRR, GRR, LKR, HEK, and VLK was 10-fold higher than WEHD, DEVD, IETD, and LETD CLs-substrates. The lowest apparent Michaelis-Menten constants $\left(\mathrm{K}_{\mathrm{M}}{ }^{\text {ap }}\right)$ corresponded to RVRRase $(37.5 \mu \mathrm{M})$ indicating a high affinity by the RVRR substrate. The inhibition of enzymatic activities by using inhibitors with different target sites for hydrolyses demonstrated that from all of the R/ Kase activities only RVRRase was a potential candidate for being a metacaspase. In parallel, zymograms and peptide-mass fingerprinting analyses revealed the identities of such Rase activities suggesting an indirect evidence of possible natural physiological substrates of MCs. We present evidence of type II-MCs not being involved in CD in D. tertiolecta, but rather in survival strategies under the stressful irradiance conditions applied in this study.
\end{abstract}

doi: $10.15698 /$ mic2019.11.696 Received originally: 29.03.2019; in revised form: 01.09.2019, Accepted 13.09.2019, Published 07.10.2019.

Keywords: Dunaliella tertiolecta, ultraviolet radiation, cell death, cell viability, metacaspases, caspase-like proteases, environmental stress.
Abbreviations:
$\mathrm{CD}$ - cell death,
CFC - chlorofluorocarbons,
$\mathrm{CL}$ - caspase-like,
$M C$ - metacaspase,
$P A B-P A R+U V A+U V B$,
$P A R$ - photosynthetic active
radiation,
$P C D$ - programmed CD,
UV - ultraviolet
UVR - UV radiation.

\section{INTRODUCTION}

The term "global change" encompasses planetary scale changes to atmospheric and ocean circulation, climate, element cycles, sea-ice and sea-level changes, food webs, biological diversity, pollution, health and fish stocks. Global change also affects exposure of organisms to solar ultraviolet B (UVB, 280-320 nm), ultraviolet A (UVA, 320-400 nm) and photosynthetically active radiation (PAR, 400-700 nm) through variations in the stratospheric ozone concentration, aerosol content and cloud cover [1-3]. Stratospheric ozone loss due to anthropogenic emission of chlorofluorocarbons (CFCs) raised the UVB doses reaching the Earth's surface owing to the ozone hole discovered in Antarctica in the mid 80 's $[1,4]$. However, even after the implementation of the Montreal Protocol to curtail CFCs emissions, ultraviolet radiation (UVR) has increased during strato- 
spheric low-ozone events in northern latitudes [5-7]. The level of ozone depletion (accounting for $\sim 6 \%$ UVB gain in the Northern Hemisphere) persists into the $21^{\text {st }}$ century caused by the long time required for ozone recovery $[1,8]$. UVR is therefore still considered a global change stressor since rapid Arctic ozone losses are predicted to occur in the future. Additionally, climate change is provoking the cooling of the stratosphere favouring ozone degradation [9, 10].

The biological effective energy per photon in the UVR wavelengths is high and it affects numerous physiological, photobiological and photochemical processes. While UVB produces deleterious effects on both terrestrial and aquatic systems, many of the effects of solar radiation are caused by wavelengths corresponding to the UVA range as well, which is not influenced by fluctuations in the stratospheric ozone [11]. Marine phytoplankton contributes to half of the world's total primary production, accounting for ca. $50 \%$ of the global atmospheric $\mathrm{CO}_{2}$ sequestration [12]. UVR has negative effects on phytoplankton 's physiology, including the inhibition of nutrient uptake, DNA and antennae damage, and decreased carbon assimilation mechanisms [11]. This decisively affects primary production in phytoplankton [13], driving microalgae into decreased cell viability and, in most species, leading to cell death in both cultures and natural communities [14-19].

The occurrence of programmed cell death (PCD) as an intrinsically instituted cellular process by which cell dismissal takes place as a consequence of biotic and/or abiotic stress has been widely reported in phytoplankton (reviewed by [20]). PCD in unicellular microalgae is justified in terms of the population level [21] or species-specific fitness effects at the community level [22] given that apparently cell death would not confer any obvious evolutionary advantage to unicellular organisms. However, most of the studies seem to disregard that the "execution" of PCD in non-metazoan organisms is significantly different from PCD in metazoans considering morphological, enzymological and functional aspects, thereby lacking a number of key molecular components of the metazoan PCD machinery [23]. The evolution of PCD in microorganisms and the accompanying terminology is beyond the scope of this paper. However, in light of the number of discrepancies concerning the interpretation of the term PCD and the actual heated-debate about revisiting the PCD nomenclature in unicellular organisms [23-25] we consider the cell death interpretation by [26] as the appropriate one for phytoplankton. Accordingly, we will simply refer to intrinsic (nonaccidental) forms of mortality as "cell death" (CD) vs. "accidental cell death" (ACD). The question arises hereby on the enzymes involved in $C D$ in phytoplankton and which is their hydrolytic nature.

Both caspase-like proteases (CLs) and metacaspases (MCs) have been appointed to participate in $\mathrm{CD}$ in phytoplankton (reviewed by [20]). Dunaliella tertiolecta cultures subjected to continuous darkness showcased massive CD and CLs measured in parallel matched the sequence of the death event [27]. Interestingly, MCs participation in the response to stress or CD has not been studied in $D$. tertio- lecta up to now, and it still remains largely unexplored in other organisms as well. MCs are members of the clan CD of cysteine proteases, presenting a caspase-hemoglobinase fold that encloses a conserved cysteine-histidine catalytic dyad. MCs are found in fungi, plants and protists (unicellular eukaryotes) and also participate in CD (reviewed by [28] and [29]). These enzymes are distinct from caspases and caspase-like proteases in terms of target site specificity. Their target substrate sites contain either arginine $(R)$ or lysine $(K)$ at the $P 1$ position, different to that of caspases or caspase-like proteases that cleave after aspartate (D) in P1 [30]. In fact, the most relevant biochemical feature of all MCs is the strict $R$ and $K$ substrate specificity, which distinguishes them from caspases [28, 31, 32]). Following this argument, what has been measured before in phytoplankton with caspase-specific substrates as "MCs activities" is not, in fact, due to MCs, because MCs do not possess caspase or caspase-like proteolytic activity [33-36]. Moreover, subtilases (SBT) from the serine protease family proteins, perform CLs hydrolysis in plants [37] after aspartate residues as for example phytaspases (aspartate-specific
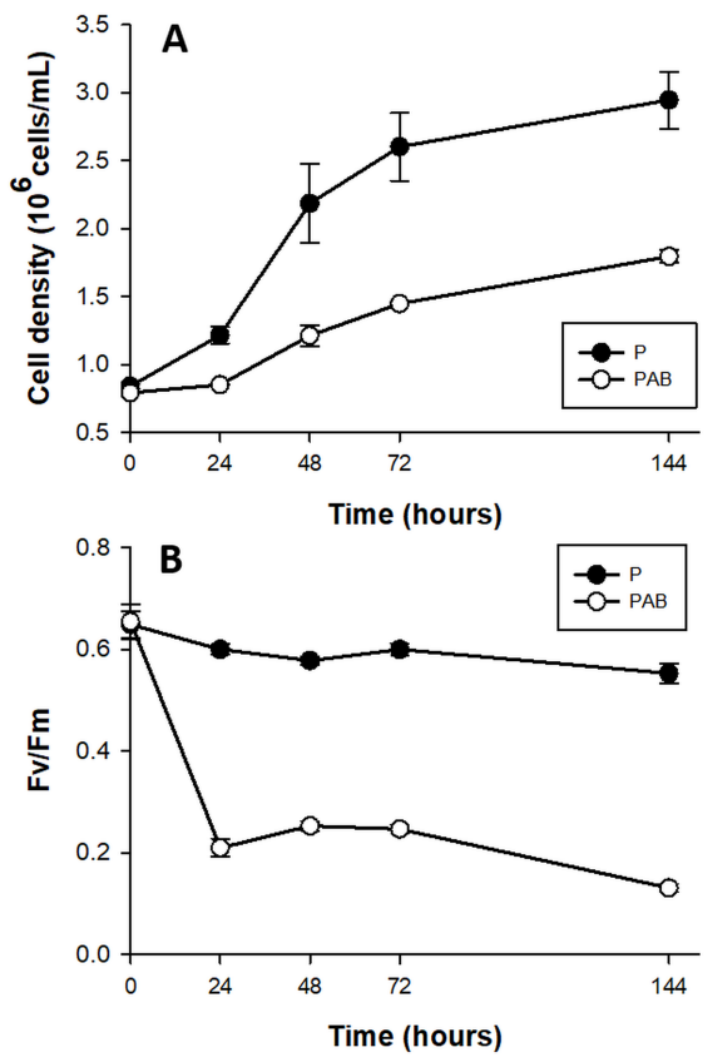

FIGURE 1. Cell abundance (A) and maximal quantum yield $\left(\mathrm{F}_{\mathrm{v}} / \mathrm{F}_{\mathrm{m}}\right)(\mathrm{B})$ in cultures of $D$. tertiolecta exposed to $\operatorname{PAR}(\mathrm{P}, \bullet)$ and to PAR + UVA + UVB (PAB, O) for six days immediately after the day 0 measurement (culture in $P$ ). Symbols are means of measurements of two independent replicate cultures and three replicate samples from each culture cylinder. Error bars indicate standard deviations. Figure reproduced with permission of The Journal of Experimental Botany [41]. 
proteases, [38, 39]), or the vacuolar processing enzyme [40]. Strikingly, CD was not detected in the unicellular green alga D. tertiolecta stressed with UVR in repeated experiments of this study. Cells survived chronic UVR exposure by induction of DNA repair mechanisms [41] in which the activation of antioxidant enzymes had a priority role scavenging reactive oxygen species (ROS) [18], alternative photoprotective mechanisms were triggered [42] and repair-genes were actively transcribed [43]. CLs were measured in these studies despite of cells not being dead, therefore suggesting an underlying UVR-managing stress role for CLs.

The aim of the present work was to study whether MCs were involved in the cellular stress response to chronic UVR exposure in the marine unicellular green alga D. tertiolecta (Viridiplantae) and the meaning of it by (1) MCs immunodetection and accumulation pattern, (2) characterising the potential MCs enzymatic activities by kinetic analysis, (3) studying enzymatic activity inhibition kinetics, (4) zymograms and peptide-mass-fingerprinting analyses to ascribe protein identities to detected proteins and, (5) to differentiate between $C L$ activities and MCs in this species resilience to $C D$ under UVR stress. Microalgae from the genus Dunaliella are well known for their extraordinarily high tolerance to abiotic stress [44]. D. tertiolecta was originally isolated from a Norwegian fjord close to the Arctic Circle. The UVR ratio and continuous treatment in the present experimental approach was selected as an extreme condition to simulate the long UVR exposure periods observed at high latitudes (key planetary locations for global change-related impact surveillance) during summer and future predicted conditions [9]. Such features make these microalgae an appropriate biological model for studying environmental stress responses.

\section{RESULTS}

Ultraviolet radiation inhibits cell growth and chlorophyll a fluorescence emission

The growth rates of $D$. tertiolecta cells (Fig. 1A) decreased 2-fold in PAB $\left(\mu_{\mathrm{PAB}}=0.58 \mathrm{day}^{-1}\right)$ compared to PAR ( $\mu \mathrm{P}=$ 1.01 day $\left.^{-1}\right)(p<0.05)$ ( $P$ treatment published in [41] and included in the plot for comparison). $F_{\mathrm{v}} / \mathrm{F}_{\mathrm{m}}$ (Fig. 1B) acutely dropped off during the first $24 \mathrm{~h}$ by $78 \%$ under $P A B$ in contrast to PAR, where $F_{v} / F_{m}$ was within the typical range for healthy cells (0.65) $\left(\mathrm{F}_{\mathrm{v}} / \mathrm{F}_{\mathrm{m}}\right.$ values reported in [41] are included for comparison).

\section{Type-II MCs are involved in UVR induced-cell stress but not in CD}

Immunodetection demonstrated the presence of Type-II MCs in D. tertiolecta. Western blots probed with the specific antibody against MC9 ( $\alpha$-AtMC9) revealed one unique band of increasing intensity from to to 144 corresponding to $60 \mathrm{KDa}$ (Fig 2A) at high antibody dilution, hence demonstrating elevated specificity. The membranes probed with

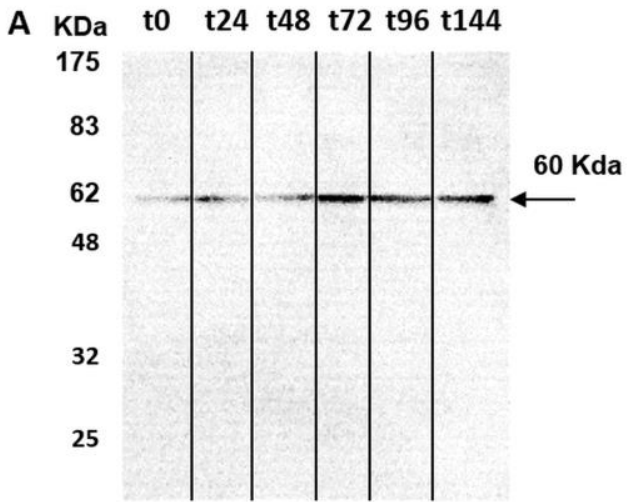

B

Pre-immune

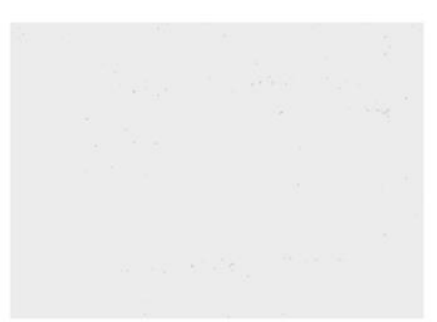

Cross reaction controls

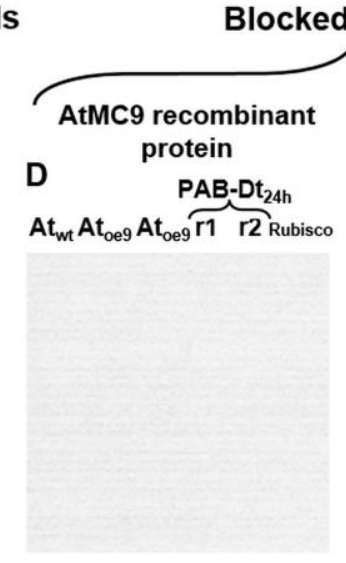

FIGURE 2. MCs immunodetection in D. tertiolecta exposed to PAR + UVA + UVB (PAB) for six days with a polyclonal antibody specific for MC9 ( $\alpha$ AtMC9) from the model plant $A$. thaliana (A); negative control with the $1^{\text {ary }}$ antibody substituted by its correspondent pre-immune sera (B); positive cross-reaction controls consisting of proteins extracted from $A$. thaliana wild type leaves (Atwt) , from $A$. thaliana over-expressing MC9 (Atoe9) and MC1 ( Atoe1) electrophoresed and western blotted together with $D$. tertiolecta samples (Dt $\mathrm{r} 1$ and $\mathrm{r} 2$ ) and commercial pure rubisco protein probed against $\alpha$-AtMC9 (C); positive control consisting of $\alpha$-AtMC9 blocked with MC9 recombinant protein (RCMC9) and probed against Atwt, Atoe9, Atoe1, Dt r1 and $\mathrm{r} 2$ and pure rubisco protein (D); negative control consisting of $\alpha$-AtMC9 blocked with pure rubisco and probed against Atwt, Atoe9, Atoe1, Dt r1 and $\mathrm{r} 2$ and pure rubisco (E). 
the pre-immune sera as control were blank (Fig 2B). Controls consisting of membranes containing proteins extracted from the Arabidopsis thaliana sub-type over-expressing MC9 (Atoe9) and with D. tertiolecta extracted proteins at $48 \mathrm{~h}-\mathrm{PAB}$ crossed-reacted with $\alpha$-AtMC9. Two unique bands of 35 and $60 \mathrm{KDa}$ respectively were detected (Fig 2C). However, no bands appeared with $\alpha$-AtMC9 in blots from proteins extracted from $A$. thaliana wild type (Atwt) leaves, and the $A$. thaliana sub-type over-expressing MC1 (Atoe1), nor with pure rubisco (Fig. 2C). The next control consisted of $\alpha$-AtMC9 blocked with the MC9 recombinant protein (RCMC9). It did not cross-react at all with any extracted proteins from $D$. tertiolecta and $A$. thaliana or with rubisco (Fig. 2D). The last control corresponded to $\alpha$-AtMC9 blocked with pure rubisco. In this case, the 60 $\mathrm{KDa}$ band from $D$. tertiolecta and the $35 \mathrm{KDa}$ band from $A$. thaliana were again detected (Fig. 2E).

The antibody specific against type II-MCs ( $\alpha$-AtII) crossed-reacted with proteins of $D$. tertiolecta showing a $26 \mathrm{KDa}$ band of increasing intensity over the experimental time (Fig. 3A) and many other less intense bands. The membranes probed with both the $\alpha$-Atll blocked with RCMC9 and with the pre-immune sera as controls were blank (Fig 3B, C). The control consisting of proteins from Atoe 9 crossed-reacted with $\alpha$-AtMC9 and two bands of $\approx 26 \mathrm{KDa}$ and $12 \mathrm{KDa}$ were observed. Proteins from Atwt and $D$. tertiolecta at $48 \mathrm{~h}-\mathrm{PAB}$ were specifically recognised by $\alpha$-AtMC9, showing one band of $\approx 26 \mathrm{kDa}$. In contrast, proteins from Atoe1 were not recognized (Fig. 3D). The antibody against type I-MCs ( $\alpha$-Atl) crossed-reacted with the pre-immune sera, therefore indicating its lack of specificity and so we avoided the use of such antibody in subsequent detections (data not shown). Dark-treated D. tertiolecta samples were used as a positive control for $\mathrm{CD}$ measured with the $C D$ fluorescent probe Sytox-green and probed with $\alpha$-AtMC9 to check for MCs involvement in $D$. tertiolecta cell demise. The $60 \mathrm{KDa}$ band accumulation pattern and positive-Sytox-green labelled dead cells proved to be inverse (Fig 4 A, B).

\section{The cleavage rate of MCs-reporter substrates is $\mathbf{1 0}$-fold higher than CLs-substrates}

MCs activities were $\approx 2$ orders of magnitude higher than $C L$ enzymatic activities. Michaelis-Menten kinetics (Fig. 5 A, B, Table 1) showed that among the MCs reporter substrates, RVRR with $\mathrm{K}_{\mathrm{M}}{ }^{\mathrm{ap}}=37.50 \mu \mathrm{M}$ (Fig. 5A) induced the highest significant enzymatic affinity, around 10 to 5 -fold higher than the other MCs substrates (Table 1). All of the CLs reporter substrates showed a $\mathrm{K}_{\mathrm{M}}{ }^{\text {ap }}$ between 58-100 $\mu \mathrm{M}$ (Fig. 5B) except DEVD with ca. 6-fold less affinity. Protease activities varied during the time-course under PAB. The most remarkable result was the RVRRase behaviour (Fig. 5C) which was different from the rest of the potential MCs substrates. It increased exponentially up to 10 -fold over time $(p<0.01)$. All of the rest of the substrates containing $R$ in P1 showed a significant $(p<0.05)$ increase at $72 \mathrm{~h}$ that

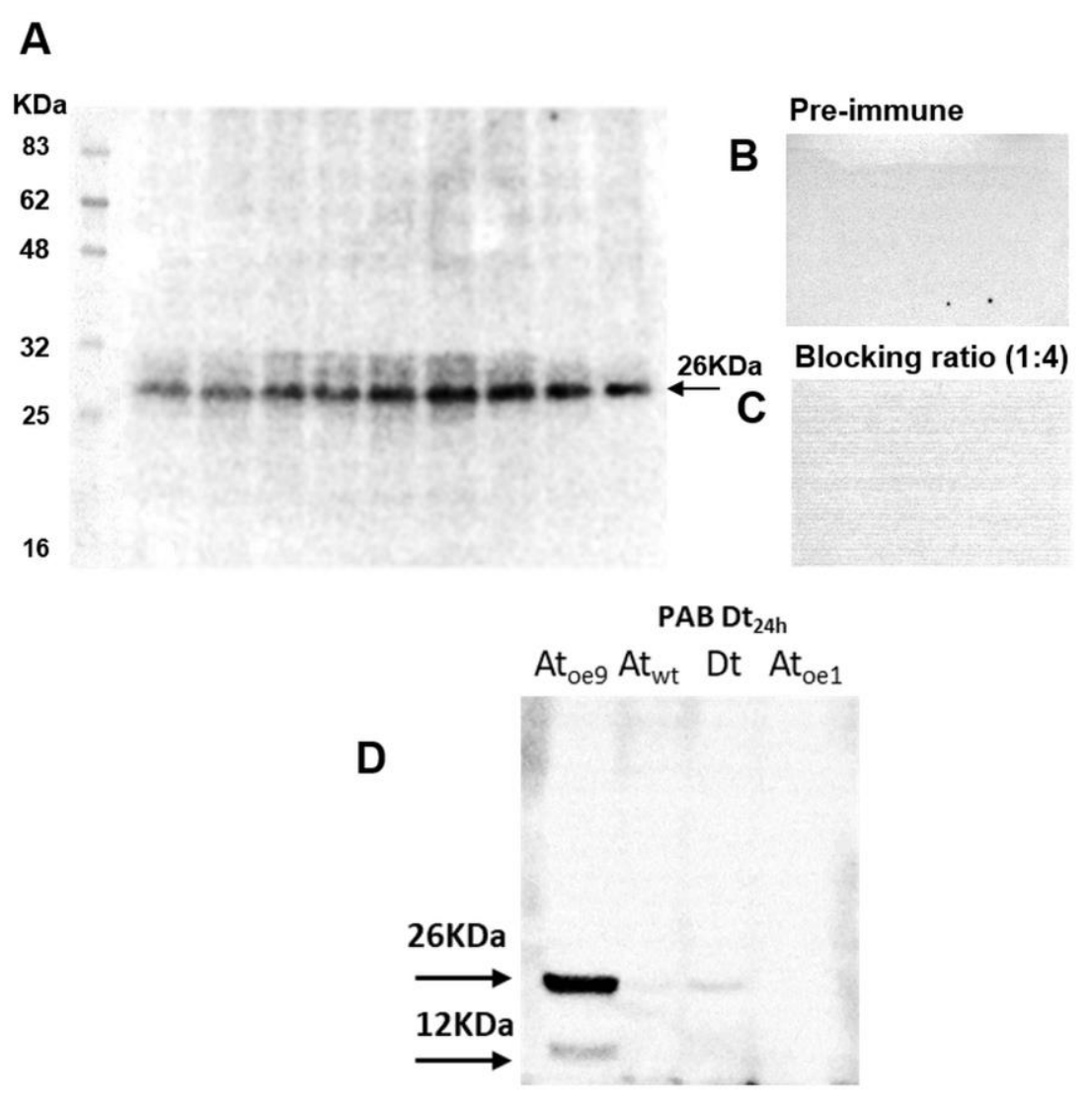

FIGURE 3. MCs immunodetection in $D$. tertiolecta exposed to PAR + UVA + UVB (PAB) for six days with a polyclonal antibody specific against MC-type II ( $\alpha$-Atll) from the model plant $A$. thaliana (A); negative control with the $1^{\text {ary }}$ antibody substituted by its correspondent pre-immune sera (B); positive control consisting of $\alpha$-Atll blocked with MC9 recombinant protein (RCMC9) and probed against Atwt, Atoe9, Atoe1, and Dt (C); positive cross-reaction controls consisting of proteins extracted from $A$. thaliana wild type leaves (Atwt) , from $A$. thaliana over-expressing MC9 (Atoe9) and MC1 (Atoe1) electrophoresed and western blotted together with $D$. tertiolecta samples (Dt) protein and probed against $\alpha$-AtIl (D). 

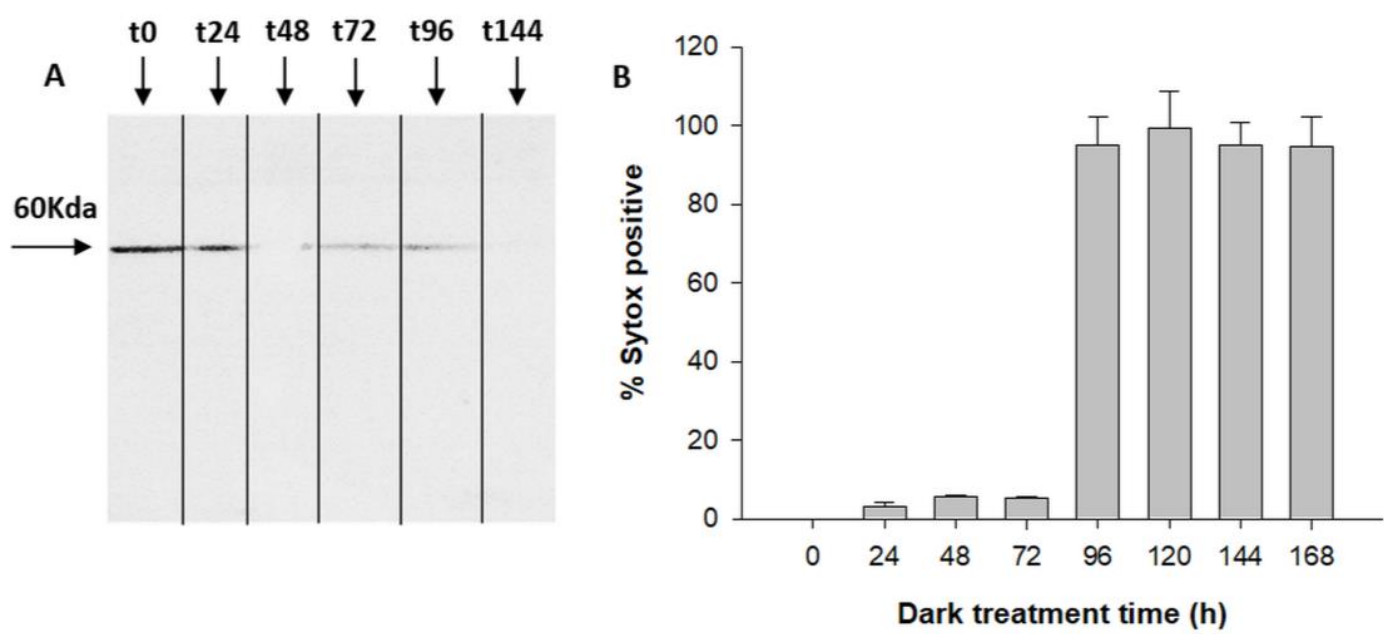

FIGURE 4. MCs immunodetection in $D$. tertiolecta during dark-induced CD (A); Percentage of dead cells based on Sytoxgreen staining for seven days darkinduced $C D$ in $D$. tertiolecta cultures (B). Symbols are means of measurements of two independent replicate cultures and three replicate samples from each culture cylinder. Error bars indicate standard deviations.

decreased by the end of the experiment (Fig. 5C). The substrates containing K in P1 raised steadily over time $(p<0.05)$ (Fig. 5C). Rase enzymatic activity in dark-induced CD samples showed a bi-phasic pattern by increasing and decreasing alternatively but there were no significant increases ( $p>0.05$ ) of activity along the time course (Fig. 5E).

IETDase, DEVDase and WEHDase activities declined during the first $24-48 \mathrm{~h}$ to recover by the end of the experiment $(p<0.05)$. LETDase activity did not change (Fig. 5D).

\section{RVRRase is a potential candidate for being a MC}

Figure 6 depicts the inhibition of the MC reporter substrates cleavage by different inhibitors and concentrations. All of the enzymatic activities with $\mathrm{R}$ or $\mathrm{K}$ in $\mathrm{P} 1$, except RVRRase (Fig. 6A) suffered a significant inhibition by nearly all the inhibitors used. The reversible serine proteases inhibitor PMSF prevented the enzymatic activity by $90 \%$ $(p<0.01)$. However, enzymatic activities were not inhibited $(p>0.05)$ by the irreversible inhibitor form 4A-PMSF. The irreversible metazoan-caspase inhibitors Z-VAD-FMK and BOC-D-FMK also inhibited the activities by ca. $90 \%$ $(p<0.05)$. In contrast, the irreversible cysteinyl-proteases inhibitor E64 did not inhibit Rase activities significantly ( $p>0.05$ ) (Fig.6B-D), but Kase activities declined 30\% (average) (Fig.6E, F). Leupeptin, a reversible serine and cysteinyl-proteases inhibitor, diminished all the enzymatic activities by $\approx 80 \%$ except for RVRRase that only dropped off by $15 \%$ (average) $(p<0.05)$. The poly-ADPribose polymerase (PARP) inhibitor benzamidine, slightly depleted all the activities around $10 \%(p<0.05)$.

In view of the lack of inhibition, RVRRase was a potential candidate for being a MC. The specific irreversible inhibitor Ac/Dec-RVRR-CMK was then tested at different concentrations as specified in the methodology section. It inhibited RVRRase activity following a logarithmic trend (Figure 7) and the $\mathrm{K}_{\mathrm{i}}^{\mathrm{ap}}$ occurred at $5.19 \mu \mathrm{M}$. Therefore, we can assume that $90-95 \%$ inhibition took place around 29.5 $\mu \mathrm{M}$.

\section{Zymograms and peptide-mass fingerprinting analyses} revealed the identities of the Rase activities

Five bands of $\approx 100 \mathrm{KDa}, 60 \mathrm{KDa}, 50 \mathrm{KDa}, 40 \mathrm{KDa}$ and $26 \mathrm{KDa}$ exhibited RVRRase activity in zymograms (Fig. 8A1). The 60 $\mathrm{KDa}$ was the clearest band detected following an accumulation pattern over the experimental time that peaked at 144 h. In GRR (Fig. 8A2) and QRR (Fig. 8A3) zymograms only the $100 \mathrm{KDa}$ and $60 \mathrm{KDa}$ bands could be clearly seen.

TABLE 1.

\begin{tabular}{llc}
\hline $\begin{array}{c}\text { AMC/AFC- } \\
\text { Reporter sub- } \\
\text { strate }\end{array}$ & Aminoacidic sequence & $\mathrm{K}_{\mathrm{M}}{ }^{\text {ap }}(\mu \mathrm{M})$ \\
\hline RVRR-AMC & Ac-Arg-Val-Arg-Arg-AMC & 37.504 \\
\hline QRR-AMC & Ac-Gln-Arg-Arg-AMC & 153.33 \\
\hline LKR-AMC & Ac-Leu-Lys-Arg-AMC & 196.09 \\
\hline GRR-AMC & Ac-Gly-Arg-Arg-AMC & 281.7 \\
\hline VLK-AMC & Ac-Val-Leu-Lys-AMC & 337.62 \\
\hline HEK-AMC & Ac-His-Glu-Lys-AMC & 452.63 \\
\hline IETD-AFC & Ac-Ile-Glu-Thr-Asp-AFC & 57.48 \\
\hline LETD-AFC & AC-Leu-Glu-Thr-Asp-AFC & 75.28 \\
\hline VEID-AFC & Ac-Val-Glu-lle-Asp-AFC & 100.00 \\
\hline WEHD-AFC & Ac-Trp-Glu-His-Asp-AFC & 186.10 \\
\hline DEVD-AFC & Ac-Asp-Glu-Val-Asp-AFC & 637.67 \\
\hline
\end{tabular}

Specific aminoacidic sequences of the Boc-7-amino-4fluoromethyl coumarin (AMC) reporters of the substrates QRR, GRR, LKR, RVRR, HEK, and VLK used to detect potential MCs; AC-7-amino-4-trifluoromethyl coumarin (AFC) reporters of the substrates WEHD, DEVD, VEID, IETD, and LEHD assayed to detect $\mathrm{CL}$ activities; $\mathrm{K}_{\mathrm{M}}{ }^{\text {ap }}$ is the apparent Michaelis-Menten constant obtained after incubation of cell lysates with increasing concentrations $(\mu \mathrm{M})$ of each reporter substrates. 

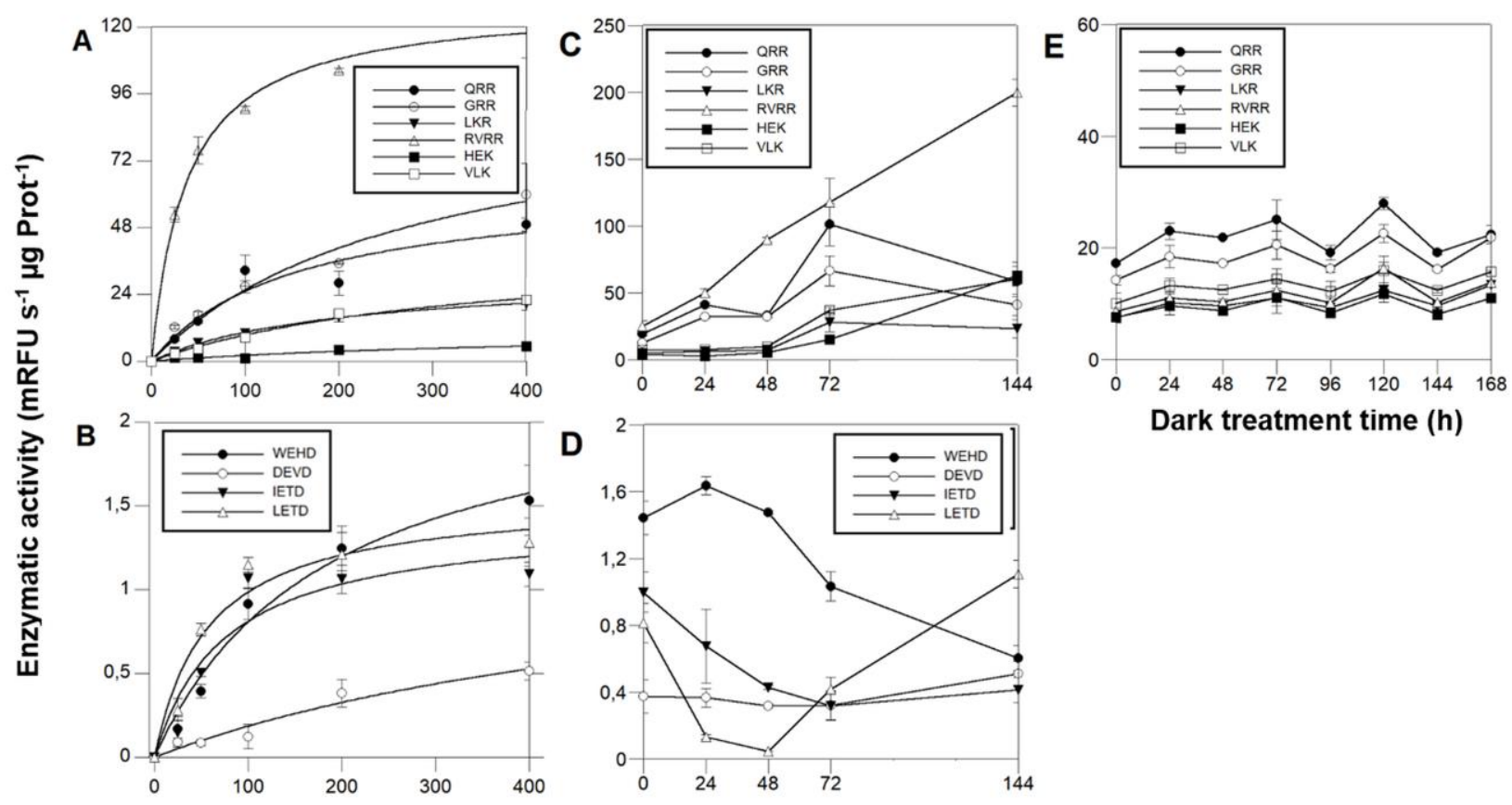

Dark treatment time (h)

Substrate concentration $(\mu \mathrm{M})$

Time under light treatment (h)

FIGURE 5. MCs and CL enzymatic activities in D. tertiolecta exposed to PAR + UVA + UVB (PAB) for six days. Michaelis-Menten kinetics showed by Boc-7-amino-4-fluoromethyl coumarin (AMC) reporters of the substrates RVRR $(\triangle), Q R R(\bullet), G R R(O), \operatorname{LKR}(\boldsymbol{\nabla})$, HEK $(\boldsymbol{\square})$, and VLK ( $\square$ ) (A); Michaelis-Menten kinetics showed by Ac-7-amino-4-trifluoromethyl coumarin (AFC) reporters of the substrates WEHD ( $\bullet$ ), DEVD (O), $\operatorname{IETD}(\boldsymbol{\nabla})$, and LEHD $(\triangle)(B)$; Cleavage activity showed by $D$. tertiolecta under PAB of (AMC) reporters of the substrates RVRR $(\triangle)$, QRR $(\bullet)$, GRR (O), LKR $(\boldsymbol{\nabla})$, HEK ( $\mathbf{\square})$, and VLK $(\square)(C)$; Cleavage activity showed by $D$. tertiolecta under PAB of (AFC) reporters of the substrates WEHD $(\bullet)$, DEVD (O), IETD $(\boldsymbol{\nabla})$, and LETD $(\triangle)(D)$; Cleavage activity showed by $D$. tertiolecta during dark-induced CD of (AMC) reporters of the substrates with R in P1 (E), symbols as in (A). Symbols are means of measurements of two independent replicate cultures and three replicate samples from each culture cylinder. Error bars indicate standard deviations.

In LKR (Fig. 8A4) zymograms bands were never well resolved, an so we had to discard it for electroelution purposes. VLK and HEK zymograms were blank (Fig. 8A5, 6). Control zymograms consisting of RVRRase (Fig. 8B1, bands B1 to B5), GRRase (Fig. 8B2, bands B6 to B8) and QRRase activities (Fig. 8B3, bands B9 to B13) from $D$. tertiolecta at 144 h-PAB, Atwt, Atoe9 and Atoe1, showed the bands described above and they were also excised for electroelution. The identity of the bands obtained in the zymograms after MaldiTOF/TOF analyses are summarised in Table 2Ssuplemental material. The highest significant similarity from bands with RVRRase activity from $D$. tertiolecta were $B 1$ and B2. Band B1 (60KDa) presented similarity with Phytochrome $\mathrm{B}$ from Cleome hassleriana, myb family transcription factor from $A$. thaliana and a $110 \mathrm{KDa} 4 \mathrm{SNc}$-Tudor domain protein from Pisum sativum, all of them Embryophytes. The analysis also revealed similarity of such band with predicted proteins from other viridiplantae. Band B2 $(\approx 40 \mathrm{KDa})$ showed significant similarity with predicted proteins from both the Bryophyte Physcomitrella patens and the Embryophyte Vitis vinifera. GRRase in-gel from $D$. tertiolecta did not display any activity (Fig. 8B2, lane $\mathrm{Dt}_{144 \mathrm{~h}}$ ). Band B10 (60KDa) with QRRase activity showed again significant similarity with predicted proteins from $P$. patens and $V$. vinifera. However, $\mathrm{B} 9(\approx 100 \mathrm{KDa})$ revealed similarity with rubisco large subunit from different Brassicaceae. Sixty-KDa bands from $A$. thaliana presented similarity among the different Rase substrates. B5 and B13 from Atwt; B3, B8 and B12 from Atoe1 and B11 from Atoe9 significantly matched with rubisco large subunit from several Embryophytes. Band B7 highly scored with a putative glyceraldehyde-3-phosphate dehydrogenase from $A$. thaliana.

\section{DISCUSSION}

UVR at the stressful doses used in this experiment (chronic exposure with a high UVR: PAR ratio) did not induce CD in the unicellular green alga D. tertiolecta [18, 41-43]. Despite that cells showed signs of stress such as inhibition of cell growth and decreased chlorophyll fluorescence emission (Fig. 1), they survived. The UVR tolerance-response has been shown to be dose-dependent, and repair under UVR is a key element in $D$. tertiolecta resilience [18, 41-43]. Enzymes typically described in CD events in phytoplankton such as $C L$ proteases are also implicated in managing the stress-response to UVR $[18,41]$, accordingly with some of the functions attributable to CLs in plants unrelated to $C D$ 
Boc-QRR-AMC (Gln-Arg-Arg)
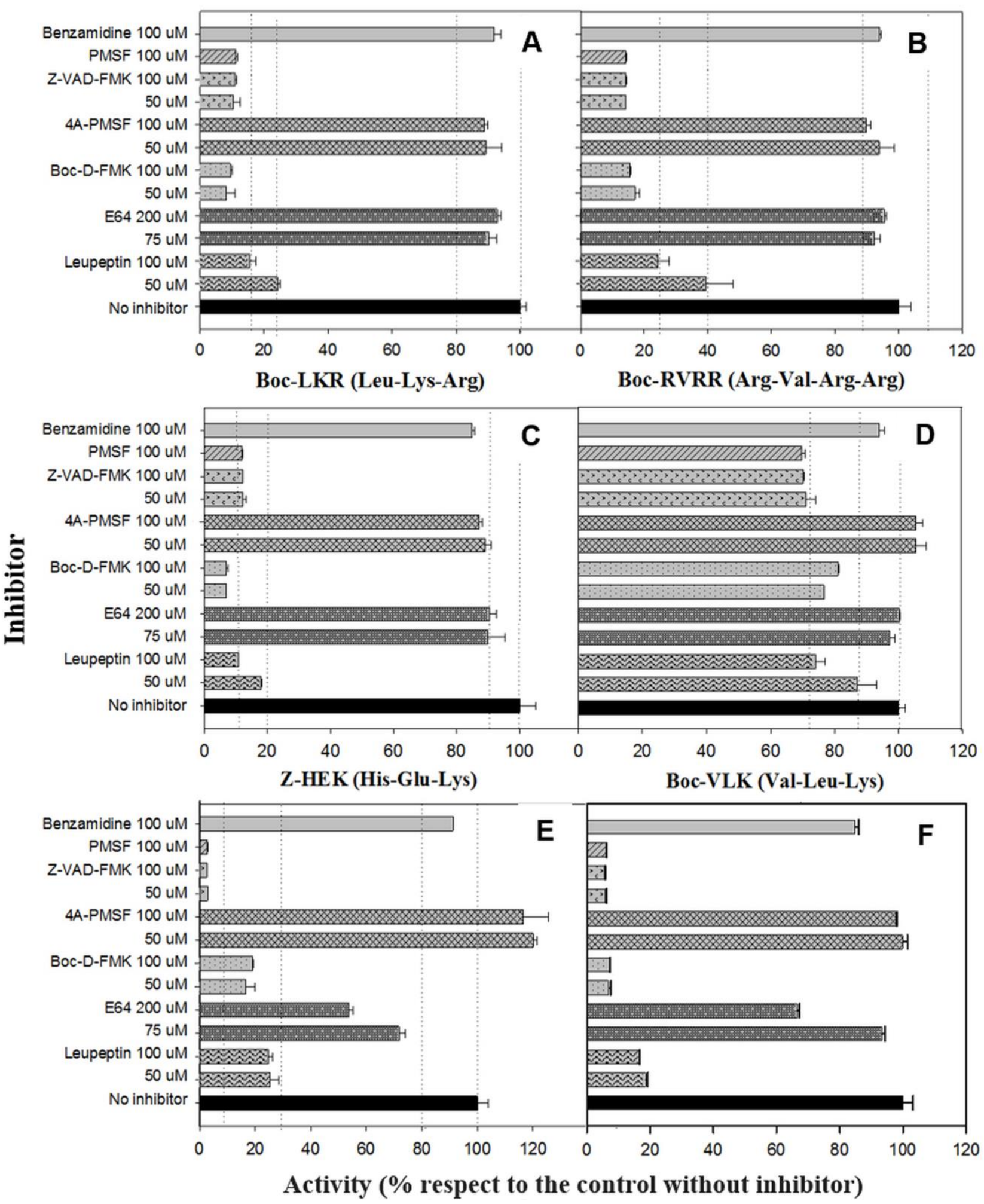

FIGURE 6. Inhibition of Rase and Kase enzymatic activities with several reversible and irreversible inhibitors at different concentrations. RVRRase (A); GRRase (B); QRRase (C); LKRase (D); VLKase (E); HEKase (F). 


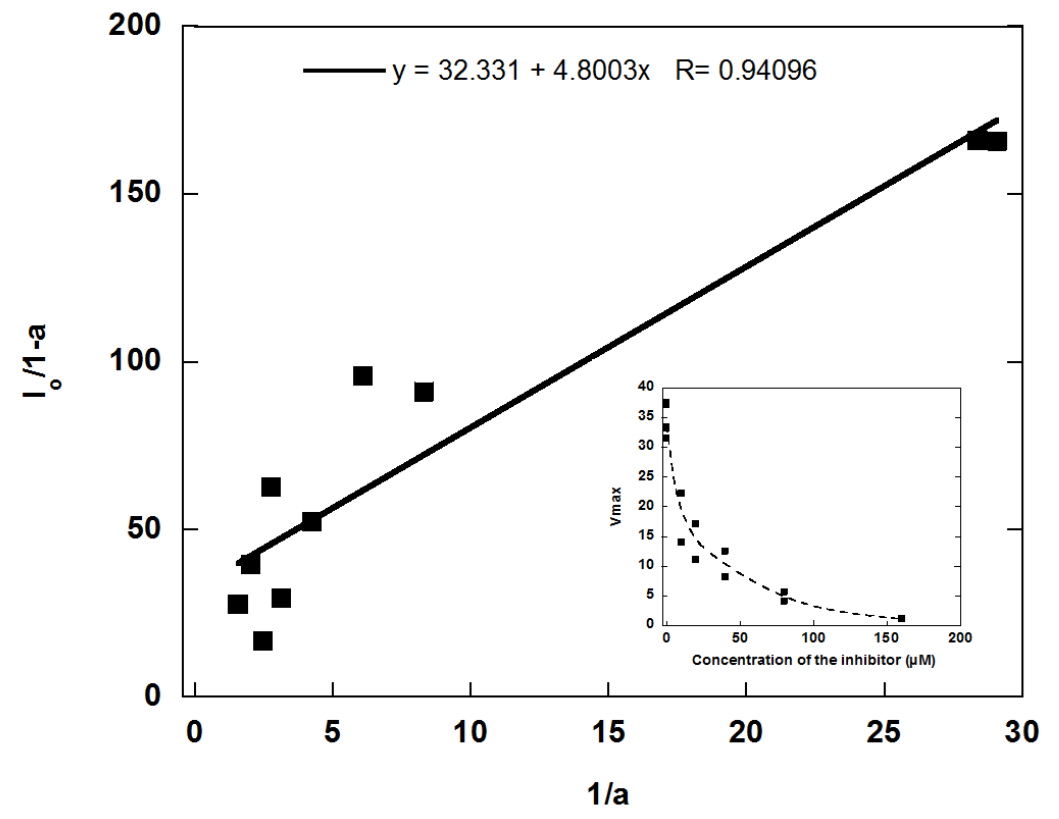

FIGURE 7. Inhibition kinetics of RVRRase activity with the Ac/Dec-RVRR-CMK irreversible inhibitor, in which a is the ratio between Vmax in the presence of the inhibitor $\left(\mathrm{Vmax}_{\mathrm{i}}\right)$ and $\mathrm{Vmax}$ in the controls in the absence of the inhibitor $\left(V \max _{0}\right)\left(a=V \max _{i} / V \max _{0}\right)$, and $\mathrm{I}_{0}$ is each of the concentrations of inhibitor tested in the assays.
[45]. The cleavage rate of CLs-reporter substrates was 10fold lower than MCs-substrates. Unfortunately, there are no antibodies against CLs as such, due to the wide variety of enzymes encompassed within the $\mathrm{CL}$ group/terminology. There are aspartate-proteases and subtilases in $D$. salina genome, thus we suggest that CLs in $D$. tertiolecta are able to hydrolyse after aspartate in $\mathrm{P} 1$, and are possibly similar to other CLs already described in Viridiplantae, although their real nature is not unraveled yet. The high resilience and tolerance of $D$. tertiolecta to increased UVR are indicators that this species could be a benefited one and have the potential to become dominant during community shifts generated within the predicted future global change scenario. However, among the mechanistic questions underlying resilience, the role and activity of MCs have not been investigated so far in this species. MCs appear to be responsible for $C D$ in phytoplankton [20]. Yet, we wonder whether MC-mediated proteolysis is directly responsible for morphological changes that occur during $C D$ in nonmetazoan organisms, or it is just one more of the versatile capacities of MCs. A key question is whether MCs are playing any role in the stress response in phytoplankton and other non-metazoan organisms, as well as in other physiological CD unrelated processes.

Immunoblot analysis demonstrated the unequivocal presence of Type-II MCs in D. tertiolecta. Type-II MCs are exclusively found in vascular plants and green algae [46] only encountered in the genomes of Chlamydomonas reinhardtii, Volvox carteri, Chlorella sorokiniana and Tetraselmis sp. up to date. They are absent in utmost other phytoplankton. Type-I MCs are also found in green algae and in nearly all eukaryotic phytoplankton [46]. In contrast, TypeIII MCs and MC-like proteases are present in most eukaryotic phytoplankton, but not in plants and green algae [46]. The antibody that was raised against Arabidopsis MC9 $(\alpha-$ AtMC9) revealed one unique $60 \mathrm{KDa}$ band of increasing intensity in parallel with progressive elevation of the UVR doses. It also cross-reacted with $A$. thaliana sub-type overexpressing MC9 (Atoe9) and MC1 (Atoe1) as positive controls (Fig 2). The Dt-Type-II-MC molecular weight is higher than those MWs reported for A. thaliana, but this divergence is reasonable considering the eminent variability existing among the different MCs from A. thaliana itself [31], as well as between the diverse organisms grouped in the different kingdoms. The high affinity of this antibody for putative Dt-Type-II-MCs epitopes is demonstrated by the high dilution of the $1^{\text {ary }}$ and $2^{\text {ary }}$ antibodies used (the concentration of antibodies used in western blots show a reverse trend with the antibody affinity). The specificity of the antibody for Type II-MC epitopes was firstly proved with $\alpha$-AtMC9 blocked with MC9 recombinant protein (RCMC9). It did not cross-react at all with any extracted proteins from $D$. tertiolecta or $A$. thaliana, because the recognition site had RCMC9 bound to it, and thus it could not bind to other MCs with their epitopes available.

Secondly, unspecific cross-reactions with any of the rubisco subunits are frequent because the antibodies that are raised against rubisco in the rabbit's diet might be present because of the heightened immune response during immunisation, and they react with the very abundant rubisco. In our case, the RCMC9-blocked antibody did not cross-react with rubisco protein, confirming the absence of unspecific cross-reactions with it. Moreover, when the $\alpha$-AtMC9 was blocked with pure rubisco protein, it clearly recognised again the $60 \mathrm{KDa}$ bands corresponding to D. tertiolecta, Atoe9 and Atoe1 (Fig. 2), reinforcing $\alpha$-AtMC9 specificity for Dt-Type-II-MCs. Immuno-isolation and co-precipitation of proteins from $D$. tertiolecta with $\alpha$-AtMC9 evidenced a band of $\approx 60 \mathrm{KDa}$ corresponding to that obtained by western blotting, thus confirming that such band corresponded to a type-II MC (data not shown). 

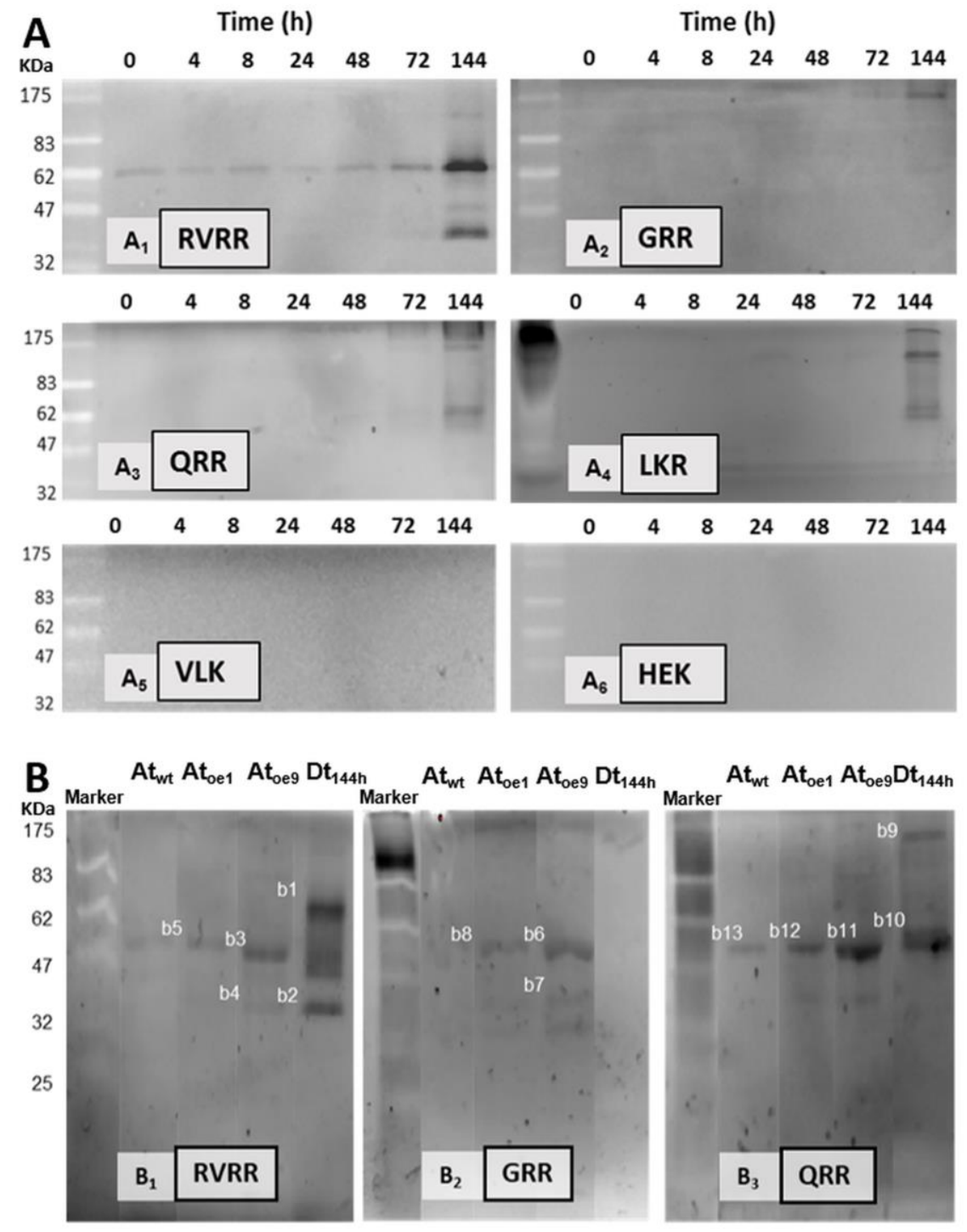

FIGURE 8. Zymograms of Rase and Kase activities in D. tertiolecta exposed to PAR + UVA + UVB (PAB) for six days. RVRRase (A1); GRRase (A2); QRRase (A3); LKRase (A4); VLKase (A5); HEK (A6). Controls consisting of zymograms of proteins extracted from $A$. thaliana wild type leaves (Atwt), from $A$. thaliana over-expressing MC9 (Atoe9) and MC1 (Atoe1) electrophoresed and western blotted together with $D$. tertiolecta samples (Dt) exposed to PAB for $144 \mathrm{~h}$ (six days).
In the third place, membranes probed with the preimmune sera as control were blank, corroborating that the proteins were not recognised by the antibody obtained from rabbits that had not been in contact with the antigen, therefore the possibility of another source for unspecific cross-reactions is eliminated. The use of a different specific $1^{\text {ary }}$ antibody against type II-MCs ( $\alpha$-AtII) also cross-reacted with proteins of $D$. tertiolecta showing a $26 \mathrm{KDa}$ band of increasing intensity over time. The same controls as above were carried out, again evidencing the participation of Type-II-MCs in the UVR-induced stress response in D. tertiolecta (Fig. 3).

Fourth, during massive CD of $D$. tertiolecta in darkness [27] Dt-Type-II-MCs accumulation pattern in western blots was opposed to the increment of dead cells (Fig 4). Survival of the cells under UVR (i.e. same experiment as this work) occurred at the expense of growth [42] and preservation of cell viability was parallel to Type-II-MCs accumulation over the experimental time (Fig. 2A).
Type-II-MCs in D. tertiolecta appear to be involved in the response to UVR. We assessed MCs activities by using specific fluorescent substrates and inhibition kinetics. The cleavage of all of the fluorogenic tri/tetra-peptide substrates with $\mathrm{R}$ or $\mathrm{K}$ residues at the $\mathrm{P} 1$ position (Table 1 ) used to detect possible MC activities in cellular lysates, was effectively inhibited by both reversible or irreversible serine protease, caspases, and cysteinyl proteases inhibitors (Fig. 6 B-F) meaning that such proteins would not probably be MCs. One of the most compelling arguments in favour of the latter is that MCs activity is not blocked by caspase inhibitors [36]. A different outcome was observed with RVRRase escaping inhibition (Fig. 6A) and enzymatic activity sharply increasing over time (Fig. $\mathbf{5 C}$ ). One limitation of this method is the use of cell lysates with a protein pool and not a purified protein. This could mask putative activities, or may yield false positive results. In this case, one must assume that a fraction of the enzymatic pool can compete for the substrate and the inhibitor and then the 
enzymatic activity assessment might not be accurate. It is therefore compulsory to assay as many tri-or tetrapeptides with $\mathrm{R}$ or $\mathrm{K}$ in $\mathrm{P} 1$ as possible, to analyse the MichaelisMenten kinetics in order to choose the right substrate concentration for the enzymatic assays, and running the enzymatic reactions with the proper irreversible inhibitors with Arg and Lys in P1. Otherwise, the assay of just one substrate would not be representative nor accurate, as it can be randomly degraded. We recommend the use of recombinant proteins product of gene cloning and expression, obtained from the cells under treatments to assay MC enzymatic activities, when possible. This is not always the case and alternative ways must be examined to keep on gaining insight into the underlying molecular mechanisms of proteases behaviour under stressful conditions. Unfortunately, we failed to clone any type-II and type I MC gene by using primers designed based on $D$. salina, and degenerate primers based on $D$. salina, $C$. reinhardtii and $A$. thaliana MCs conserved domains, and so we were not able to further analyse whether the accumulation of transcripts correlated with the enzymatic activities or what exactly was the activity of the expressed gene. However, due to the lack of inhibition of RVRRase by the various protease inhibitors described above, RVRRase is a potential candidate for being a MC.

We then synthetized the specific irreversible inhibitor Ac/Dec-RVRR-CMK which inhibited the activity by $95 \%$ at $29.5 \mu \mathrm{M}$ (Fig. 7) pointing to RVRRase as a presumable MC. R/Kase enzymatic activities showed a steady state behaviour with non-significant differences between protease activity and/or time in D. tertiolecta dark-induced-CD (Fig. $\mathbf{5 E}$ ), implying that RVRRase activity was not involved in $D$. tertiolecta dark-induced $\mathrm{CD}$, and supporting the data obtained by western blotting and flow cytometry, already suggesting that MCs are not involved in $C D$ in this green alga.

All the potential MC activities were characterised from zymograms and by mass spectrometry analyses to unravel the identities of the enzymes associated with K/Rase activity. Kase activity was not detected in any zymogram, which is counterintuitive attending to Kase enzymatic activities measured in vitro (Fig. $\mathbf{5 C}$ ). Peptide mass spectrometry results suggest that the bands with Rase enzymatic activity obtained in D. tertiolecta and A. thaliana zymograms (B1 to B13) would not be MCs, which is equally in disagreement with the assayed enzymatic activities (Fig. 5C).

Since $\alpha$-AtMC9 and $\alpha$-Atll antibodies showed elevated affinity and specificity for MCs epitopes in D. tertiolecta, one might expect that protein sequences in $D$. salina most likely present high similarity with $A$. thaliana due to low $D$. salina and D. tertiolecta SNP rate [44]. Based on the presence of type-II MCs specific conserved catalytic amino acid residues (i.e. HYSGHGT and CHSG) obtained after multiple sequence alignments of Type II MCs from A. thaliana and $D$. salina with Clustal Omega (EMBL-EBI), the protein Dusal.0158s00011.1 from D. salina showed the best E-value compared to type II MCs from A. thaliana, but also great similarity between putative type II-MCs and almost all type II-MCs from $A$. thaliana were found (Figure 1Ssupplemental material). Such $D$. salina sequence was used to compare the protein fragments obtained from $D$. tertiolecta in the MALDITOF/TOF analyses and to check for significant homologous domains with putative MCs from D. tertiolecta by using Pfam, Interpro and Prosite ([47-49]). As expected, no typical metacaspase domains were present in any of the proteins obtained in the zymograms.

However, it is intriguing that some of the proteins identified in the zymograms by MALDITOF/TOF analyses are natural physiological substrates of $M C$ in other $\mathrm{Vi}$ ridiplantae. For instance, the Tudor staphylococcal nuclease (TSN) protein found in B1 from D. tertiolecta (Fig. 8B, Table 2S-Supplemental material) was the first natural plant MC substrate identified in Picea abies [50] and it has also been reported to be a MC target of $A$. thaliana and Populus trees [51]. The glyceraldehyde-3-phosphate dehydrogenase found in bands B4 and B7 from A. thaliana (Fig. 8B, Supplemental Table 2S) is a physiological specific substrate of the yeast MC Yca1 [52]. More intriguing is that rubisco large subunit was found in QRR and GRR zymograms from D. tertiolecta; in RVRR, QRR and GRR zymograms from $A$. thaliana overexpressing MC9 and MC1 and A. thaliana wild type (Fig. 8B, Supplemental Table S2). Surprisingly, rubisco has not been clearly identified as a physiological substrate of MCs, although a small rubisco subunit has been found in A. thaliana MC9 degradome [32]. It is noticeable that rubisco was absent in the mass spectrometry analyses of RVRRase zymograms from $D$. tertiolecta, while it appeared in RVRRase zymograms bands from Atoe9 with extremely high fluorescent intensity, and also in Atoe1 with significantly less activity (Fig. 8B, Supplemental Table 2S). Rubisco is by far the most abundant protein on earth $[53,54]$, hence, it is reasonable to think that it can show up in mass spectrometry analysis as remaining fragments, witness of former degradation events, despite the fact that it has a very low turnover due to its high abundance and its constitutive feature within the cells. Still, this would not explain why the rubisco band was absent in RVRRase zymograms from $D$. tertiolecta. Our data are inconclusive regarding the identities of the proteins found by peptide-mass fingerprinting. Yet, it is also possible that highly abundant proteins such as rubisco co-migrate at the same molecular weight as RVRRases, masking the true responsible for the protease activities which are present.

\section{CONCLUDING REMARKS}

This study demonstrates the presence of Type-II-MC(s) in the marine unicellular green alga $D$. tertiolecta (Viridiplantae) and their participation in the cellular stress response to ultraviolet exposure. Specifically, the following events occurred in parallel: (1) the accumulation pattern and specificity of the immunodetected Dt-Type-II MC shown in western blots over time, (2) the increased hydrolysis of Boc-RVRRase-AMC substrate along the experimental course, (3) the lack of RVRRase activity blockage by caspase inhibitors, (4) the full inhibition of RVRRase activity by the irreversible Ac/Dec-RVRR-CMK inhibitor and, (5) the lowest apparent Michaelis-Menten constant $\left(\mathrm{K}_{\mathrm{M}}{ }^{\mathrm{ap}}\right)$ of all 
$\mathrm{R} /$ Kases observed corresponded to RVRRase, indicating elevated affinity by RVRR substrate; (6) the increased hydrolytic signal in RVRRase zymograms over time. Taken together our data strongly support the hypothesis that RVRRase enzymatic activity might be a type-II MC. In contrast, all of the rest of Rase and Kase activities were disqualified to be considered as MCs due to their unspecific behaviour during inhibition. Furthermore, RVRRase activity did not increase in $D$. tertiolecta dark-induced CD meanwhile immunodetected Dt-Type-II-MCs accumulation and increase of dead cells showed an inverse trend. This evidences that type-II MCs are not involved in $C D$, but rather in survival strategies under stressful irradiance conditions in this chlorophyte, in agreement with the heterogeneity of proteolytic functions described for MCs in plants [28, 30, 56]. Given the pleiotropic feature of MCs, we consider that measuring MCs activities alone is not sufficient to ascribe a death process where they intervene, as PCD. Although zymograms and peptide-mass fingerprinting revealed the identities of Rase activities suggesting an indirect evidence of possible natural physiological substrates of MCs, we cannot accurately conclude at present whether this is the case nor whether there are also type-I MCs involved in the response, and thus further investigation is required by using different proteomic-based approaches.

The present study highlights the influential ecological consequences that changes in stratospheric ozone levels may have on the responses of phytoplankton UVR exposure at the molecular level and how that is regulated. Phytoplankton is at the base of the food webs constituting a key component of biogeochemical cycles. Research on the stress response of phytoplankton at the molecularecophysiology level is essential in a rapidly changing environment consequence of global change, since in our planet, half of the organic carbon incorporation is due to phytoplankton [12]. Although caution is necessary and general responses cannot be ruled out from laboratory studies to field conditions, light structures biological communities and differential responses of phytoplankton species to fluctuating UVR can lead to shifts in species composition within natural populations, favouring species that are able to better cope with stressful irradiances. This constitutes a key component of species specificity within the actual global change scenario, ultimately regulating biodiversity, ecosystem stability and ecosystem services.

\section{MATERIALS AND METHODS}

\section{Experimental set-up and culture conditions}

Batch axenic cultures of the unicellular chlorophyte $D$. tertiolecta Butcher (CCAP 19/6B) originally isolated from a Norwegian fjord were grown in artificial seawater medium [55] enriched with $f / 2$ nutrients [56], in sterile acrylic cylinders (Plexiglas $X T^{\circledast} 29080$ ) transparent to UVR. Cultures were maintained at $16^{\circ} \mathrm{C}$ at $120 \mu \mathrm{mol}$ quanta $\mathrm{m}^{-2} \mathrm{~s}^{-1}$ continuous irradiance. To avoid cell shading, cells were subjected to continuous stirring and aeration through $0.2 \mu \mathrm{m}$ fiberglass filters (Millipore). When cultures reached mid-log phase, they were verified for bacterial contamination by using DAPI (Molecular Probes, Oregon, USA) according to [15], and the cells were then ex- posed to PAR+UVA+UVB (PAB) for six days (144 h). Sampling started after switching the UVR on. Cells were harvested every $24 \mathrm{~h}$. The stressful UVR effect was assayed in four independent replicate cultures $(\mathrm{N}=4)$ and samples from each culture cylinder were analysed for each variable aim of study.

The irradiance conditions were achieved by covering the experimental cylinders with an Ultraphan-295 UBT $500 \mathrm{~mm}$ cut-off filter (Digefra, Munchen, Germany) which transmitted PAR, UVA, and UVB (PAB). This filter has no transmission below $295 \mathrm{~nm}$ (UVC). Since UVC does not reach the Earth's surface, it is not realistic to include the UVC band in any experimental set-up studying environmental responses. PAR irradiance at $120 \mu \mathrm{mol}$ photons $\mathrm{m}^{-2} \mathrm{~s}^{-1}$ was obtained by using Optimarc 250W lamps (DuroTest, USA) and measured using an Ocean Optics SMS 500 spectroradiometer (Sphaereoptics, New Hampshire, USA) calibrated after NPL standards with a cosine-corrected sensor. Experimental UVR fluence rates were provided by Qpanel-340 lamps simulating the natural solar radiation conditions reaching the upper photic zone and measured with an Ocean Optics SMS 500 spectroradiometer mentioned above. Spectra were measured in the range 200$800 \mathrm{~nm}$. All light measurements were carried out inside the experimental cylinders once they were wrapped with the UVC cut-off filter. Experimental irradiances (unweighted) were 9.5 $\mathrm{Wm}^{-2}$ UVA and $0.5 \mathrm{Wm}^{-2}$ UVB (UVR:PAR ratio $=0.38$ ) according to [42]. The experimental PAR:UVR ratio was specifically chosen to be able to analyse the contribution of total UVR on the physiological response, without being masked by both the effects of high PAR and UVA and UVB wavelengths separation. For comparison with other studies, weighted irradiances corresponding to the measured light spectra were the same as those calculated by [18] by using the appropriate biological weighting functions (BWFs).

\section{Cell abundance and in vivo chlorophyll a fluorescence}

Cellular density was determined in $1 \mathrm{~mL}$ fresh samples by flow cytometry (Accuri, BD, USA) under blue excitation with chl a as the trigger according to [57]. The maximal quantum yield of Photosystem II (PSII) fluorescence $\left(F_{v} / F_{m}\right)$ was measured with a Water-PAM fluorometer (Waltz, Effeltrich, Germany) as described in [41]. High $F_{v} / F_{m}$ values indicate that cells are in good physiological condition, whereas a decrease of $F_{v} / F_{m}$ indicates stress and/or photoinhibition.

\section{MCs immunodetection.}

For MCs detection and accumulation, SDS- PAGE was performed according to [27] on an equal protein concentration loading basis. For MCs immunodetection and band analyses, western blots were probed with polyclonal antibodies against type I and type II MCs from the model plant $A$. thaliana [58]. The antibody against type I MC ( $\alpha$-AtI) was checked for cross reactivity at 1:7000 dilution and subsequently incubated with an anti-rabbit secondary antibody at 1:15000 dilution. The antibody crossing with all type II MCs ( $\alpha$-AtII) and the antibody specific against MC9 ( $\alpha$-AtMC9) were used at 1:10000 dilution and subsequently incubated with an $\alpha$-rabbit $2^{\text {ary }}$ antibody at 1:20000 dilution.

The following controls were carried out to check for specificity and affinity of the antibodies: (1) each $1^{\text {ary }}$ antibody was substituted with its correspondent pre-immune sera at the same dilution than the used $1^{\text {ary }}$ and $2^{\text {ary }}$ antibodies described just above; (2) as positive controls, proteins extracted from 
A. thaliana wild type leaves and from two sub-types of $A$. thaliana over-expressing MC9 (Atoe9, [58]) and over-expressing MC1 ( Atoe1, [59]) were electrophoresed and western blotted together with $D$. tertiolecta samples incubated in PAB during 48h; (3) the MC9 recombinant protein [31] was used as a positive control and as the $\alpha$-AtMC9-blocking peptide to ensure absolute specificity of the $1^{\text {ary }} \alpha$-AtMC9. The blockage to binding site ratio was 1:4 (antibody/pure recombinant protein) in moles; (4) primary antibodies were also blocked with commercial pure rubisco (Sigma-Aldrich) to ensure no recognition of this protein when using the $2^{\text {ary }} \alpha$-rabbit antibodies; (5) a secondary antibody non-specific cross-reactivity control was carried out by incubating the membranes with only the $2^{\text {ary }}$ antibody in the absence of the $1^{\text {ary }}$ antibody; (6) dark-treated $D$. tertiolecta samples were used as a positive control for CD as described in [57]. The intensity of cross-reactions was quantified by chemiluminescence (ECL-Advanced; GE Healthcare) in a Gel Logic Image Analyser (Eastman-Kodak, Rochester, NY).

\section{$\mathrm{CL}$ and $\mathrm{MC}$ enzymatic activities}

Cells $(50 \mathrm{~mL}$ ) were harvested by centrifugation, resuspended in $2 \mathrm{~mL}$ lysis buffer containing $50 \mathrm{mM}$ HEPES (pH 7.3), $100 \mathrm{mM}$ $\mathrm{NaCl}, \quad 10 \%$ sucrose, $0.1 \% \quad 3$-[(3-cholamidopropyl)dimethylammonio]-1-propanesulphonate (CHAPS), and $10 \mathrm{mM}$ dithiothreitol, and sonicated (UP50H, Hielscher $\mathrm{GmbH}$, Germany) on ice $3 \times 10$ s allowing 10 min recovery after each cycle. Cell lysates were mixed with different concentrations of Boc-7-amino-4-fluoromethyl coumarin (AMC) reporters of the substrates QRR, GRR, LKR, RVRR, HEK, and VLK (catalogue \# 3122-v, 3142-v3141-v, 3155-v, 3215-v, 3104-v, respectively, Peptanova $\mathrm{GmbH}$, Germany) were used to detect potential MCs. Ac-7-amino-4-trifluoromethyl coumarin (AFC) reporters of the substrates WEHD, DEVD, IETD, and LETD (catalogue \# $3186 v, 3171 v, 3195 v$, and 3198v, respectively, Peptanova $\mathrm{GmbH}$, Germany) were used to detect $\mathrm{CL}$ activities. The specific aminoacidic sequences of the substrates can be found in Table 1. The emitted fluorescence was measured in the kinetic mode for $4 \mathrm{~h}$ at $16^{\circ} \mathrm{C}$ (excitation $360 \mathrm{~nm}$, emission 460 $\mathrm{nm}$ ) in a microplate fluorescence reader (FL-600, BIO-TEK, USA). The total protein content was measured by using the bicinchoninic acid assay (BCA) [60]. The enzymatic activity was expressed as relative fluorescence units per time and per equal protein content (RFU s ${ }^{-1}$ prot $\left.^{-1}\right)$.

To measure the enzymatic activities accurately over the experimental time, the optimal substrate concentration had to be determined first. For this, enzymatic assays were carried out by incubating the cell extracts of $48 \mathrm{~h}$ under PAB with 25 , $50,100,200$ and $400 \mu \mathrm{M}$ of each of the reporter substrates. A Michaelis-Menten kinetic was modelled to calculate the apparent Michaelis-Menten constant $\left(\mathrm{K}_{\mathrm{M}}{ }^{\mathrm{ap}}\right)$. The term "apparent" is adopted when $K_{M}$ is observed under conditions that would hinder the determination of its true value (e.g. the presence of a competitive substrate/ reversible inhibitor of any kind). Due to our enzymatic activity being measured in cell lysates and not in purified proteins, we assume $\mathrm{K}_{\mathrm{M}}{ }^{\text {ap }}$ as the correct parameter.

\section{Inhibition of the enzymatic activity}

To get a better insight on the enzyme kinetics for the MCs reporter substrates, samples exposed to PAB during $48 \mathrm{~h}$ were incubated for $1 \mathrm{~h}$ at $16^{\circ} \mathrm{C}$ (previously to the activity assay) with the following reversible and irreversible protease inhibitors, at the indicated final concentrations: (1) benzamidine at $100 \mu \mathrm{M}$; (2) phenylmethylsulfonyl fluoride (PMSF) at $100 \mu \mathrm{M}$; (3) benzyloxycarbonyl-Val-Ala-Asp (OMe) fluoromethylketone (ZVAD-FMK) at 100 and $50 \mu \mathrm{M}$; (4) 4A-phenylmethylsulfonyl fluoride (4A-PMSF) at 100 and $50 \mu \mathrm{M}$; (5) benzyloxycarbonyl Asp (OMe) fluoromethylketone (Boc-D-FMK) at 100 and 50 $\mu \mathrm{M}$; (6) trans-Epoxysuccinyl-L-leucylamido(4-guanidino) butane (E64) at 200 and $75 \mu \mathrm{M}$; (7) Leupeptin at 100 and $50 \mu \mathrm{M}$. Detailed inhibition target groups can be consulted in Table S1Supplemental material.

\section{Synthesis of Ac/Dec-RVRR-CMK irreversible inhibitors and RVRRase inhibition kinetics}

One of the most striking results obtained in the enzyme kinetics assays was the behaviour of RVRRase activity. Due to the lack of commercial RVRR inhibitors and our need of studying its inhibition, we synthesized two irreversible RVRRase inhibitors. For these syntheses, a convergent strategy was employed according to which two peptidic fragments ( $A / A^{\prime}$ and $B$ ) were synthetized separately and then coupled. The peptidic chain contained in fragments $A$ and $A^{\prime}$ was prepared by using solid phase methodology on a 2-chlorotrityl chloride (CTC) resin [61] applying the Fmoc strategy [62] as follows: the CTC resin was properly derivatized with $\mathrm{Fmoc}-\mathrm{Arg}(\mathrm{Boc})_{2}-\mathrm{OH}$ using $\mathrm{N}, \mathrm{N}$-diisopropylethylamine (DIPEA) in $\mathrm{N}, \mathrm{N}$-dimethylformamide (DMF). Then, the Fmoc (9-fluorenylmethoxycarbonyl) protecting group was removed by treatment with $20 \%$ solution of piperidine in DMF and the following Fmoc protected aminoacid, Fmoc-Val-OH, was loaded onto the resulting resin by the action of $\mathrm{N}, \mathrm{N}^{\prime}$-diisopropylcarbodiimide (DIC) in the presence of 1-hydroxybenzotriazole (HOBt) in DMF. The same sequence of Fmoc deprotection and peptidic coupling was repeated twice to introduce sequentially a new unit of Fmoc-Arg (Boc) $2^{-}$ $\mathrm{OH}$ and $\mathrm{CH}_{3} \mathrm{COCl}$ for $\mathrm{A}$ or $\mathrm{CH}_{3}\left(\mathrm{CH}_{2}\right)_{8} \mathrm{COCl}$ for $\mathrm{A}^{\prime}$. At the end of the solid phase peptide synthesis, the resin-bound peptide was cleaved from the resin by treatment with a AcOH:TFE: $\mathrm{CH}_{2} \mathrm{Cl}_{2}$ (7:2:1) mixture to obtain the fragments $A$ and $A^{\prime}$, respectively. Fragment $B$ was prepared as described by [63] as follows: Commercially available Boc-Arg (Mtr)-OH was treated with isopropyl chloroformate in the presence of 4methylmorpholine followed by reaction with $\mathrm{CH}_{2} \mathrm{~N}_{2}$ in $\mathrm{Et}_{2} \mathrm{O}$ to obtain the corresponding diazo derivative. Final treatment with methanolic $\mathrm{HCl}$ afforded the fragment $\mathrm{B}$. Fragments $\mathrm{A}$ or $A^{\prime}$ and $B$ were coupled by using DIC, HOBt and DIPEA to obtain the corresponding peptides, which were finally subjected to a treatment with a solution of trifluoroacetic acid (TFA) in $\mathrm{MeOH}$ to remove the Mtr (2,3,6-trimethyl-4methoxybenzenesulfonyl ) and Boc (tert-butyloxycarbonyl) protecting groups to yield the peptides Ac-Arg-Val-Arg-ArgCMK and Dec-Arg-Val-Arg-Arg-CMK (Ac/Dec-RVRR-CMK).

The inhibition kinetics was assayed according to the Easson \& Stedman model [64] for the calculation of the apparent inhibition constant $\left(\mathrm{K}_{\mathrm{i}} \mathrm{ap}\right)$ when using irreversible inhibitors. Samples exposed to $48 \mathrm{~h}$ PAB were pre-incubated with 10, 20, 40,80 and $160 \mu \mathrm{M}$ of the inhibitor (final concentrations) for $1 \mathrm{~h}$. The RVRRase activity was then measured by adding $50 \mu \mathrm{M}$ of Boc-RVRR-AMC substrate according to the optimal substrate concentration obtained previously in the MichaelisMenten kinetics assay. The substitution of cell extracts by buffer and no addition of RVRR substrate to the cell extracts in the reaction mix were used as negative controls. 
Zymograms and peptide-mass-fingerprinting analyses SDS-PAGE was carried out as described previously and gels were renaturalised according to [65 and references within] to obtain active enzymes. For this purpose, gels were incubated twice in $0.05 \mathrm{M}$ Tris- $\mathrm{HCl}$ buffer with $20 \%$ Triton X-100 at pH 7.4 for $10 \mathrm{~min}$. Subsequently, they were again incubated twice in the same buffer without Triton X-100 for $10 \mathrm{~min}$. The reconstitution of the enzymatic activity is possible because the denaturation agents transforms proteins into a random coil conformation and the removal of these agents is accompanied by the recovery of the native structure, therefore activity. The enzymatic activities were detected and quantified. Gels were incubated in the reaction buffer containing each of the AMCreporters of the substrates QRR, GRR, LKR, RVRR, HEK, and VLK described in the enzymatic activities assay section (one gel, one substrate) overnight at $4^{\circ} \mathrm{C}$. Gels were analysed in the image analyser by using a $535 \mathrm{~nm}$ detection filter. The recovery of the enzymatic activity was always tested by comparing the in-gel activities to native protein extracts incubated with the appropriate fluorescent substrates and it was never lower than $95 \%$.

The protein bands were excised from the gel and electroeluted by using an electrophoretic-protein-concentration device ISCO 1750 (ISCO Inc., Lincoln, NE). Electroelution was performed through $10 \mathrm{KDa}$ pore dialyses membranes in 25 $\mathrm{mM}$ Tris -Gly buffer with $0.1 \%$ SDS at $\mathrm{pH}$ 8.3. The electroeluted proteins were digested with trypsin. The generated fragments were analysed by nanoscale liquid chromatography (nano LC) coupled to peptide mass fingerprinting by using a MALDI (matrix-assisted laser desorption ionization) source and tandem time-of-flight (TOF/TOF) mass analysers (4700 Proteomics Analyzer, Applied Biosystems). For protein identification, peptide lists from the MS analysis were submitted to the Mascot search engine version 2.1 (Matrix Science, London, UK) integrated in GPS ExplorerTM v3.5 (AB Sciex). A combined (MS+MS/MS) type analysis was run by aligning similar fragments with those sequences uploaded in NCBInr Uniprot databases restricted to Viridiplantae as search criteria.

\section{Statistical analyses}

Data were checked for normality by Shapiro-Wilks' test and homoscedasticity by Cochran's and Levene's tests. Variables met all criteria to perform parametric tests. Any significant influence of the cylinders for the cultures was discarded by a nested ANOVA ( $p>0.05)$. Statistical significance of treatment effects was analysed by using 2 Way-ANOVA followed by posthoc Sidak, Tukey or Newman-Keuls (considering $p<0.05$ and/or $\mathrm{p}<0.01$ as significant). All analyses were performed by using the GLM (general linear model) procedure with main effects and interaction terms. When appropriate the three pseu-

\section{REFERENCES}

1. Shanklin J (2010). Reflections on the ozone hole. Nature 465: 34-35. doi: 10.1038/465034a

2. Mckenzie RL, Aucamp PJ, Bais AF, Björn LO, Ilyas M and Madronich $S$, Norval M (2011). Ozone depletion and climate change: impacts on UV radiation. Photochem Photobiol Sci 10(2):182-98. doi: 10.1039/c0pp90034f

3. Bais AF et al. (2018). Environmental effects of ozone depletion, UV radiation and interactions with climate change: UNEP Environmental doreplicates samples from each cylinder were considered replicates, since the nested ANOVA was not significant, and so the mean of the values was used. Statistical analyses were carried out by using the software Statistica v12 (Statsoft, Inc.).

\section{ACKNOWLEDGMENTS}

The present work was supported by Research Grants CTM2010-17216 from the Ministry for Science and Innovation (MICCIN) and P08-03800 from the Regional Science Research Programme (Junta de Andalucia) Spain, to MS. MTM, AP and CGG were funded by PhD grants (FPI) associated with the above-mentioned research grants. MLP was supported by a postdoctoral return grant ("I Plan Propio de Investigación y Transferencia, University of Málaga), Spain. ICS was funded by a PhD grant (FPU) from the Ministry for Education, Spain, associated to research grants to FS. We thank Frank Van Breusegem for providing the antibodies raised against $A$. thaliana metacaspases, preimmune sera, metacaspase- 9 recombinant protein, $A$. thaliana wild type and overexpressing MC1 and MC9 leaves, as well as for discussions and comments on the manuscript. We thank Jon Magnuson for discussions on metacaspase genes from D. salina. We thank the two anonymous reviewers for constructive criticisms.

\section{SUPPLEMENTAL MATERIAL}

All supplemental data for this article are available online at www.microbialcell.com.

\section{CONFLICT OF INTEREST}

Authors declare no conflict of interest.

\section{COPYRIGHT}

(C) 2019 Mata et al. This is an open-access article released under the terms of the Creative Commons Attribution (CC BY) license, which allows the unrestricted use, distribution, and reproduction in any medium, provided the original author and source are acknowledged.

Please cite this article as: M. Teresa Mata, Armando Palma, Candela García-Gómez, María López-Parages, Víctor Vázquez, Iván Cheng-Sánchez, Francisco Sarabia, Félix López-Figueroa, Carlos Jiménez and María Segovia (2019). Type II-Metacaspases are involved in cell stress but not in cell death in the unicellular green alga Dunaliella tertiolecta. Microbial Cell 6(11): 494-508. doi: 10.15698/mic2019.11.696

Effects Assessment Panel, update 2017. Photochem Photobiol Sc 17(2):127-179. doi: 10.1039/c7pp90043k

4. Farman JC, Gardiner BG and Shanklin JD (1985). Large losses of total ozone in Antarctica reveal seasonal $\mathrm{ClOx} / \mathrm{NOx}$ interaction. Nature 315: 207-210. doi: 10.1038/315207a0

5. Keil M, Jackson DR and Hort MC (2007). The January 2006 low ozone event over the UK. Atmospheric Chemistry and Physics 7(3): 961-972. doi: 10.5194/acp-7-961-2007 
6. Sinnhuber BM, Stiller, G, Ruhnke R, von Clarmann T, Kellmann S and Aschmann J (2011). Artic winter 2010/2011 at the brink of an ozone hole. Geophysic Res Lett 38(24): L24814. doi: 10.1029/2011GL049784

7. Strahan SE, Douglass AR and Newman PA (2013). The contributions of chemistry and transport to low Arctic ozone in March 2011 derived from Aura MLS Observations S.E. J Geophysic Res 118 (3): 1563-1576. doi: 10.1002/jgrd.50181

8. Bais AF, McKenzie RL, Bernhard G, Aucamp PJ, Ilyas M, Madronich S and Tourpali $\mathrm{K}$ (2015). Ozone depletion and climate change: impacts on UV radiation. Photochem Photobiol Sci 14(1):19-52. doi: 10.1039/c4pp90032d

9. WMO statement on the status of the global climate in 2007 (2008). World Meteorological Organization. ISBN 92-63-11031-1.

10. Weatherhead EC and Andersen SB (2006). The search for signs of recovery of the ozone layer. Nature 441: 39-45. doi: $10.1038 /$ nature 04746

11. Häder DP (2011). Does enhanced Solar UV-B radiation affect Marine Primary producers in their natural habitats? Photochem Photobiol 87(2): 263-266. doi: 10.1111/j.1751-1097.2011.00888.x

12. Falkowski PG and Raven JA (2007). Aquatic Photosynthesis. 2nd Edition. Princeton University Press. ISBN: 9780691115511.

13. Beardall J and Raven JA (2004). The potential effects of global climate change on microalgal photosynthesis, growth and ecology. Phycologia 43: 26-40. doi: 10.2216/i0031-8884-43-1-26.1

14. Moharikar S, D`Souza JS, Kulkarni AB and Rao BJ (2006). Apoptoticlike cell death pathway is induced in unicellular chlorophyte Chlamydomonas reinhardtii (Chlorophyceae) cells following UV irradiation: detection and functional analyses. J Phycology 42: 423-433. doi: 10.1111/j.1529-8817.2006.00207.x

15. Jiménez C, Capasso JM, Edelstein CL, Rivard CJ, Lucia S, Breusegem S, Berl T and Segovia M (2009). Different ways to die: Cell Death modes of the unicellular chlorophyte Dunaliella viridis exposed to various environmental stresses are mediated by the caspase-like activity DEVDase. J Exp Bot 60(3):815-28. doi: 10.1093/jxb/ern330

16. Llabrés $M$ and Agustí S (2006). Picophytoplankton cell death induced by UV radiation: evidence for oceanic Atlantic communities. Limnology and Oceanography 51: 21-29. doi: 10.4319/lo.2006.51.1.0021

17. Llabrés $M$ and Agustí S (2010). Effects of ultraviolet radiation on growth, cell death and the standing stock of Antarctic phytoplankton. Aquatic Microbial Ecology 59: 151-160. doi: 10.3354/ame01392

18. Bouchard JN, García-Gómez C, Lorenzo MR and Segovia M (2013). Differential effect of ultraviolet exposure (UVR) in the stress response of the Dinophycea Gymnodinium sp. and the Chlorophyta Dunaliella tertiolecta: mortality versus survival. Marine Biology 160: 2547-2560. doi: 10.1007/s00227-013-2247-z

19. Sobrino C, Segovia M, Neale PJ, Mercado JM, García-Gómez C, Kulk G, Lorenzo MR, Camarena T and van de Poll WH (2014). Effect of CO2, nutrients and light on Coastal Plankton. IV. Physiological responses. Aquatic Biology 22: 77-93. doi: 10.3354/ab00590

20. Bidle KD (2016). Programmed cell death in unicellular phytoplankton. Current Biol 26: R594-R607. doi: 10.1016/j.cub.2016.05.056

21. Orellana MV, Pang WL, Durand PM, Whitehead K and Baliga NS (2013). A role for programmed cell death in the microbial loop. PLoS ONE 8: e62595. doi: 10.1371/journal.pone.0062595

22. Durand PM, Choudhury R, Rashidi A and Michod RE (2014). Programmed death in a unicellular organism has species-specific fitness effects. Biol Lett 10: 20131088. doi: 10.1098/rsbl.2013.1088
23. Carmona-Gutiérrez D et al. (2018). Guidelines and Recommendations on yeast cell death nomenclature. Microbial Cell 5(1): 4-31. doi: 10.15698/mic2018.01.607

24. Pandey SS, Singh S, Pathak C and Tiwari BS (2018). Programmed Cell Death: A Process of Death for Survival- How Far Terminology Pertinent for Cell Death in Unicellular Organisms. J Cell Death 11: 1-4. doi: $10.1177 / 1179066018790259$

25. Durand PM and Ramsey G (2018). The Nature of Programmed Cell Death. Biol Theory 14 (1):30-41. doi: 10.1007/s13752-018-0311-0

26. Berges JA and Choi CJ (2014). Cell death in algae: Physiological processes and relationships with stress. Perspectives in Phycology 1(2): 103-112. doi: 10.1127/pip/2014/0013

27. Segovia M., Haramaty L, Berges JA and Falkowski PG (2003). Cell death in the unicellular chlorophyte Dunaliella tertiolecta. A Hypothesis on the Evolution of Apoptosis in Higher Plants and Metazoans. Plant Physiol 132: 99-105. doi: 10.1104/pp.102.017129

28. Tsiatsiani L, van Breusegem F, Gallois P, Zavialov A, Lam E and Bozhkov PV (2011). Metacaspases. Cell Death Diff 18: 1279-1288. doi: 10.1038/cdd.2011.66

29. Minina EA, Coll NS, Tuominen $\mathrm{H}$ and Bozhkov PV (2017). Metacaspases versus caspases in development and cell fate regulation. Cell Death Diff 24(8): 1314-1325. doi: 10.1038/cdd.2017.18

30. Van der Hoorn RA (2008). Plant proteases: from phenotypes to molecular mechanisms. Ann Rev Plant Biol 59: 191-223. doi: 10.1146/annurev.arplant.59.032607.092835

31. Vercammen D, van de Cotte B, De Jaeger G, Eeckhout D, Casteels $P$, Vandepoele K, Vanderberghe I, Van Beeumen J, Inzé D and Van Breusegem F (2004). Type II metacaspases Atmc4 and Atmc0 of Arabidopsis thaliana cleave substrates after arginine and lysine. J Biol Chem 279: 45329-45336. doi: 10.1074/jbc.M406329200

32. Tsiatsiani L, Timmerman E, De Bock PJ, Vercammen D, Stael S, van de Cotte B, Staes A, Goethals M, Beunens T, Van Damme P, Gevaert K and Van Breusegem $F$ (2013). The Arabidopsis metacaspase9 degradome. Plant Cell 25: 2831-2847. doi: 10.1105/tpc.113.115287

33. Koonin EV and Aravind L (2002). Origin and evolution of eukaryotic apoptosis: the bacterial connection. Cell Death Diff 9: 394-404. doi: $10.1038 / \mathrm{sj} / \mathrm{cdd} / 4400991$

34. Vercammen D, Declercq W, Vandenabeele $P$ and Van Breusegem $F$ (2007). Are metacaspases caspases? J Cell Biol 179(3): 375-380. doi: 10.1083/jcb.200705193

35. Salvesen B, Stenvik J, Rossetti C, Saugstad OD, Espevik T and Mollnes TE (2010). Meconium-induced release of cytokines is mediated by the TRL4/MD-2 complex in a CD14-dependent manner. Mol Immunol 47: 1226-1234. doi: 10.1016/j.molimm.2009.12.015

36. Salvesen GS, Hempel A and Coll NS (2015). Protease signaling in animal and plant-regulated cell death. FEBS J 283(14): 2577-2598. doi: 10.1111/febs.13616

37. Schaller A, Stintzi A, Rivas S, Serrano I, Chichkova NV, Vartapetian $A B$, Martínez D, Guiamét JJ, Sueldo DJ, van der Hoorn RAL, Ramírez V and Vera $P$ (2017). From structure to function - a family portrait of plant subtilases. New Phytologist 218: 901-915. doi: 10.1111/nph.14582

38. Vartapetian AB, Tuzhikov Al, Chichkova NV, Taliansky $M$ and Wolpert TJ (2011). A plant alternative to animal caspases: subtilisinlike proteases. Cell Death Diff 18: 1289-1297. doi: 10.1038/cdd.2011.49

39. Galiullina RA, Kasperkiewicz P, Chichkova NV, Szalek A, Serebryakova MV, Poreba M, Drag M and Vartapetian AB (2015). Substrate Specificity and Possible Heterologous Targets of Phytaspase, a Plant 
Cell Death Protease. J Biol Chem 290: 24806-24815. doi: 10.1074/jbc.M115.675819

40. Hara-Nishimura I and Hatsugai N (2011). The role of vacuole in plant cell death. Cell Death Diff 18: 1298-1304. doi: 10.1038/cdd. 2011.70

41. García-Gómez C, Parages ML, Jiménez C, Palma A, Mata MT and Segovia M (2012). Cell survival after UV radiation stress in the unicellular chlorophyte Dunaliella tertiolecta is mediated by DNA repair and MAPK phosphorylation. J Exp Bot 63: 5259-5274. doi: 10.1093/jxb/ers185

42. Segovia M, Mata MT, Palma A, García-Gómez C, Lorenzo R, Rivera $A$ and Figueroa FL (2015). Dunaliella tertiolecta (Chlorophyta) Avoids Cell Death Under Ultraviolet Radiation by Triggering Alternative Photoprotective Mechanisms. Photochem Photobiol 91: 1389-1402. doi: 10.1111/php.12502

43. García-Gómez C, Mata MT, Van Breusegem F and Segovia M (2016). Low-steady-state metabolism induced by elevated $\mathrm{CO} 2$ increases resilience to UV radiation in the unicellular green-algae Dunaliella tertiolecta. Environ Exp Bot 132: 163-174. doi 10.1016/j.envexpbot.2016.09.001

44. Polle JE, Tran D and Ben-Amotz A (2009). History, Distribution and Habitats of Algae of the Genus Dunaliella Teodoresco (Chlorophyceae). In: Ben-Amotz A, Polle JE and Rao DVS, editors. The Alga Dunaliella: Biodiversity, Physiology, Genomics \& Biotechnology. CRC Press, Boca Raton, FL; pp. 1-13.

45. Van der Hoorn RAL and Rivas S (2018). Unravelling the mode of action of plant proteases. New Phytologist 2018: 879-881. doi: 10.1111/nph.15156

46. Choi CJ and Berges JA (2013). New types of metacaspases in phytoplankton reveal diverse origins of cell death proteases. Cell Death Dis 4: e490. doi: 10.1038/cddis.2013.21

47. El-Gebali S, Mistry J, Bateman A, Eddy SR, Luciani A, Potter SC, Qureshi M, Richardson L, Salazar GA, Smart A, Sonnhammer ELL, Hirsh L, Paladin L, Piovesan D, Tosatto SCE and Finn RD (2018). The Pfam protein families database in 2019. Nucleic Acids Res 47: D427D432. doi: 10.1093/nar/gky995

48. Mitchell AL et al. (2018). InterPro in 2019: improving coverage, classification and access to protein sequence annotations. Nucleic Acids Res 47: D351-D360. doi: 10.1093/nar/gky1100

49. Sigrist CJA, de Castro E, Cerutti L, Cuche BA, Hulo N, Bridge A, Bougueleret $L$ and Xenarios I (2012). New and continuing developments at PROSITE. Nucleic Acids Res 41: D344-D347. doi: $10.1093 /$ nar/gks1067

50. Sundström JF, Vaculova A, Smertenko AP, Savenkov El, Golovko A, Minina E, Tiwari BS, Rodríguez-Nieto $S$, Zamyatnin Jr AA, Välineva T, Saariketuu J, Frilander MJ, Suarez MF, Zavialov A, Ståhl U, Hussey PJ, Silvennoinen O, Sundberg E, Zhivotovsky B and Bozhkov PV (2009). Tudor staphylococcal nuclease is an evolutionarily conserved component of the programmed cell death degradome. Nat Cell Biol 11: 1347-1354. doi: 10.1038/ncb1979

51. Bollhoner B, Jokipii-Lukkari S, Bybdell J, Stael S, Adriasola M, Muniz L, Van Breusegem F, Ezcurra I, Wingsle G and Tuominen H (2018). The function of two type II metacaspases in woody tissues of Populus trees. New Phytologist 217: 1551-1565. doi: 10.1111/nph.14945

52. Silva A, Almeida B, Sampaio-Marques B, Reis MIR, Ohlmeier S, Rodrigues $F$, do Vale $A$ and Ludovico $P$ (2011). Glyceraldehyde-3phosphate dehydrogenase (GAPDH) in a specific substrate of yeast metacaspase. Biochim Biophys Acta 1813: 2044-2049. doi: 10.1016/j.bbamcr.2011.09.010

53. Ellis RJ (1979). The most abundant protein in the word. Trends Biochem Sci 4: 241-244. doi: 10.1016/0968-0004(79)90212-3

54. Miziorko HM and Lorimer GH (1983). Ribulose-1,5-Bisphophate Carboxylase-Oxygenase. Ann Rev Biochem 52: 507-535. doi: 10.1146/annurev.bi.52.070183.002451

55. Goldman JC and McCarthy JJ (1978). Steady state growth and ammonium uptake of a fast-growing marine diatom. Limnology and Oceanography 23: 695-703. doi: 10.4319/lo.1978.23.4.0695

56. Guillard RRL and Ryther JH (1962). Studies of marine planktonic diatoms. I. Cyclotella nana Hustedt and Detonula confervacea (Cleve) Gran. Can J Microbiol 8: 229-239. doi: 10.1139/m62-029

57. Segovia M and Berges JA (2009). Inhibition of caspase-like activities prevents the appearance of reactive oxygen species and darkinduced apoptosis in the unicellular chlorophyte Dunaliella tertiolecta. J Phycol 126-137. doi: 10.1111/j.1529-8817.2009.00733.x

58. Vercammen D, Belenghi B, van de Cotte B, Beunens T, Gavigan JA, De Rycke $R$, Brackenier $A$, Inzé $D$, Harris $J L$ and Van Breusegem $F$ (2006). Serpin1 of Arabidopsis thaliana is a suicide inhibitor for metacaspase 9. J Mol Biol 364(4):625-36. doi: 10.1016/j.jmb.2006.09.010

59. Brackenier A (2006). Functional analysis of metacaspases in Arabidopsis thaliana. Faculty of Sciences, Ghent University, Ghent, Belgium. Available at: http://hdl.handle.net/1854/LU-3007695

60. Smith PK, Krohn RI, Hermanson GT, Mallia AK, Gartner FH, Provenzano MD, Fujimoto EK, Goeke NM, Olson BJ and Klenk DC (1985). Measurement of protein using bicinchoninic acid. Anal Biochem 150: 76-85. PMID: 3843705.

61. Barlos K, Gatos D and Schäfer W (1991). Synthesis of Prothymosin $\alpha($ ProT $\alpha)$-a Protein Consisting of 109 Amino Acid Residues. Angewandte Chemie International Edition 30: 590-593. doi: 10.1002/anie.199105901

62. Sarabia F, Chammaa S and García-Ruíz C (2011). Solid Phase Synthesis of Globomycin and SF-1902 A5. J Organ Chem 76: 2132-2144. doi: 10.1021/jo1025145

63. Sun A, Shoji M, Lu YJ, Liotta DC and Snyder JP (2006). Synthesis of EF24-Tripeptide Chloromethyl Ketone: A Novel Curcumin-Related Anticancer Drug Delivery System. J Med Chem 59: 3153-3158. doi: 10.1021/jm051141k

64. Easson LH and Stedman E (1936). The absolute activity of cholineesterase. Proceedings of the Royal Society of London, Series B: Biological Sciences 121(821): 142-164. doi: 10.1098/rspb.1936.0055

65. Kameshita I and Fujisawa $\mathrm{H}$ (1989). A sensitive method for detection of calmodulin-dependent protein kinase II activity in sodium dodecyl sulfate-polyacrylamide gel. Anal Biochem 183: 139-143. doi: 10.1016/0003-2697(89)90181-4 